\title{
Treatment of Hyperpigmentation in Darker Skins
}

\section{Savas Yayli*}

Department of Dermatology, Faculty of Medicine, Karadeniz Technical University, Trabzon, Turkey

*Corresponding author: Savas Yayli, Department of Dermatology, Faculty of Medicine, Karadeniz Technical University, Trabzon, Turkey, Tel: 904623775388 ; Email: savasyayli@gmail.com

Rec date: Dec 14, 2014; Acc date: Dec 28, 2014; Pub date: Jan 02, 2015

Copyright: $@ 2015$ Yayli S, This is an open-access article distributed under the terms of the Creative Commons Attribution License, which permits unrestricted use, distribution, and reproduction in any medium, provided the original author and source are credited.

\section{Introduction}

Darker skin or skin of colour means higher Fitzpatrick skin types in a wide range of racial and ethnic groups referring to persons from African, Asian, Native American, Middle Eastern and Hispanic backgrounds. Darker skin types are characterized by higher content of melanin, higher eumelanin to pheomelanin ratio. This is an advantage for protection against ultraviolet (UV) radiation, however it also makes darker skin more vulnerable to postinflammatory dyspigmentation $[1,2]$.

Pigmentary disorders, especially hyperpigmentation is one of the most common complaints in darker skin, and the management is often challenging. A recent review by Cestari et. al listed most common acquired hyperpigmentations in darker skin including melasma, Post Inflammatory Hyperpigmentation (PIH), acanthosis nigricans, phytophotodermatosis, dermatosis papulosa nigra, erythema dyschromicum perstans, periorbital hyperpigmentation, flagellate dermatosis, confluent and reticulated papillomatosis of Gougerot and Carteaud, cervical poikiloderma and primary cutaneous amyloidosis [3]. This presentation will particularly focus on the treatment options of melasma and PIH in darker skin.

\section{Treatment options in Melasma and PIH in Darker Skin}

Before the treatment, one should identify and treat any underlying dermatosis or contributing factors. Moreover, the treatment should have rational goals. One should also keep in mind the options with multi-therapy approach. Sun protection should be central with sunscreens and physical barriers, such as hats and clothing which will reduce sun exposure [4].

For melasma, current treatments available remain unsatisfactory. Topical combination therapies are more effective. Triple Combination (TC) including hydroquinone, retinoids and steroids is most effective with clear adverse effects such as erythema and peeling. Chemical peels, especially superficial ones, are generally effective. Laser and light therapies have mixed with an increased risk of irritation and PIH [5].

For PIH, firstly one should aim to treat underlying disorders. It often takes many months. Topical therapy is typically effective for epidermal PIH. Chemical peels and lasers may help in recalcitrant hyperpigmentation. All treatments should be used with great caution to prevent irritation and worsening of PIH [4].

\section{Topical treatments}

A list of skin lightening agents are listed in Table 1 [2]. The largest group in those agents is tyrosinase inhibitors, and the most wellknown agent is hydoquinone which is often considered as "topical gold standart" in the melasma and hyperpigmentation treatments [4]. However, in last decade concerning the safety reasons about hydroquinone such as ochronosis or theoretical risk of malignancy, many newer agents are in the market [6]. Beside those newers, fixed TC including hydroquinone $4 \%$, tretinoine $0.05 \%$, flucinolon acetonide $0.01 \%$ is shown as the therapy with highest evidence - still little controlled studies - in Latin guide of melasma or recent reviews. If there is an irritation or allergy to one of compounds of this TC, one may use it as dual combinations. In Latin guide for treatment of melasma, second line therapies are TC plus peels or microdermabrasion, and lastly lasers and light sources [4,7].

\begin{tabular}{|c|c|}
\hline Mechanism of action & Compound \\
\hline \multirow[t]{8}{*}{ Tyrosinase inhibition } & Arbutin \\
\hline & Azelaic acid \\
\hline & DeoxyArbutin \\
\hline & Hydroquinone \\
\hline & Liquorice extract \\
\hline & Mequinol \\
\hline & N-Acetylglucosamine \\
\hline & N-Acetyl-4-S-cysteaminylphenol \\
\hline \multirow[t]{3}{*}{ Reduction in melanosome transfer } & Niacinamide \\
\hline & Retinoids \\
\hline & Soybean trypsin inhibitor \\
\hline \multirow[t]{2}{*}{ Interaction with copper } & Ascorbic acid \\
\hline & Kojic acid \\
\hline \multirow[t]{2}{*}{ Stimulation of keratinocyte turn over } & Glycolic acid \\
\hline & Retinoids \\
\hline \multirow[t]{2}{*}{ Inhibition of melanosome maturation } & Arbutin \\
\hline & DeoxyArbutin \\
\hline Inhibition of protease-activated receptor-2 & Soybean trypsin inhibitor \\
\hline Oxidation and break down of melanin & Lignin peroxidase \\
\hline
\end{tabular}

Table 1: Skin lightening agents [2].

Hydroquinone is an older depigmenting cream which is effective in $2 \%-5 \%$ formulations. The most well-known adverse effects are irritation, contact allergy, exogenous ochronosis. It is sold with prescription in many countries. It is also a component of famous Kligman's Formula: Hydroquinone 5\%, tretinoine $0.1 \%$, dexamethasone $0.1 \%[8]$. 
Page 2 of 3

One of the few randomized controlled studies comparing fixed TC and hydroquinone $4 \%$ in Asian melasma patients showed that TC had superior efficacy (64.2\% and 39.4\%) in 8-weeks, in all assessed parameters including Melasma Area and Severity Index score and Global Severity Score (GSS). TC was associated with more but mostly mild adverse effects [9].

A recent letter by Kandhari et al. pointed out that topical treatment for melasma might cause many side effects in skin of colour. In their study, 69 melasma patients with darker skin treated topically with or without TC showed frequent side effects including erythema, acneiform eruptions, telangiectasias, hypertrichosis and rosaeca like eruption. Of those side effects, erythema and hypertrichosis are significantly higher in TC group [10]. Patient education is crucial on that topical therapy including hydroquinone and TC to prevent mentioned side effects.

One example for newer therapies in melasma that has been recently reported in the literature is the effects of methimazole. İt is a potent peroxidase inhibitor, and peroxidase is known as important in final steps of melanogenesis. Methimazole is not melanocytotoxic, even at high concentrations. A recent report by Malek et al showed impressive results with methimazole in a patient with hydroquinone resistant melasma after 2-month therapy [11].

Another example of newers is 4-n-butylresorcinol, which has been shown a higher inhibitory capacity on human tyrosinase activity than hydroquinone, arbutin and kojic acid [12]. Another potent tyrosinase inhibitor, decapeptide- 12 has been recently shown very effective with a marked improvement of PIH after 8-week therapy. It is not also melanocytotoxic [13].

\section{Chemical peels}

Chemical peels are generally effective in darker skin, especially superficial ones. Because of increased risk of $\mathrm{PIH}$, deep peelings should be avoided. Pretreatment with a course of hydroquinone may improve the results. Topical retinoids should be stopped before seven days. Standard options are glycolic acid 10-70\%, salicyclic acid $20-30 \%$, trichloroacetic acid (TCA) $10-25 \%$ and Jessner's solution. In a recent review, the newers are listed as tretinoin, pyruvic acid, $\beta$-lipohydroxy acid, mandelic acid and amino fruit acids [14].

In terms of glycolic acid and salicylic acid, both peels have been shown beneficial for melasma and PIH. A study by Grimes et al. showed that five salicyclic acid peels $20-30 \%$ with 2-week interval for PIH had more than $75 \%$ improvement in $80 \%$ of patients with skin of colour [15]. In another study by Grover et al, eight glycolic acid peels $10-30 \%$ with 2 -week interval was found useful for superficial scarring and melasma [16].

For the newer peels, Ilknur et al who compared the efficacy of amino fruit acid (AFA) and glycolic acid, showed that both of them were effective, however AFA peel was beter tolerated [17].

A recent study from Egypt, comparing the efficacy of different formulations of TCA $(20 \%, 25 \%, 30 \%)$ and different wavelenght of qswitched Nd:YAG laser (532 nm and $1064 \mathrm{~nm}$ ) found that TCA $25 \%$ is the most effective, according to the mean improvement percentage of MASI scores. Q-switched Nd:YAG laser with $532 \mathrm{~nm}$ had the highest complications [18].

\section{Lasers and light sources}

Lasers are the last options for the recalcitrant cases of melasma and $\mathrm{PIH}$ with great caution. Many reports have pointed out that the safest and efficient laser for melasma and PIH in darker skin was q-switched Nd:YAG laser with its longer wavelenght (1064 nm). Q-switched Ruby laser with $694 \mathrm{~nm}$ is not recommended in darker skin. Intense pulse light (IPL) has mixed results [19].

Some reports have shown that low fluence q-switched Nd:YAG laser with $1064 \mathrm{~nm}$ was beneficial for melasma and PIH in darker skin. A study by Cho et al. [20] from Korea has reported high patient satisfaction (50-100\% improvement) in 18 of 25 patient with five sessions q-switched Nd:YAG laser with-2 week interval. The fluence was between $2.0-3.5 \mathrm{j} / \mathrm{cm}^{2}$. Another study with the same laser by Choi [21] et al.has showed that the mean MASI scores were significantly decreased after five sessions with 1-week interval. The fluence was also 2.0-3.5 j/ $\mathrm{cm}^{2}$. However, a study by Wattanakrai has reported only temporary improvement with 5 sessions q-switched Nd:YAG laser with 1-week interval. The fluence was between 3.0-3.8 j/cm². Four of 22 patients had rebound hyperpigmentation, and all patients had recurrence of melasma [22].

In a recent study by Chung et al., they compared the efficacy of pulse-in-pulse IPL (PIP-IPL) and the combination of IPL and qswitched Nd:YAG laser. After 6 months, they found same efficacy on melanin index for both therapy, and concluded that PIP-IPL might be a safe and promising treatment for melasma in darker skin [23].

In terms of fractional lasers, in a study by Wanitphakdeedecha et al., they concluded that fractional photothermolysis laser $1410 \mathrm{~nm}$ was safe and temporary effective, but long term follow up was stil needed. They suggested that only $5 \%$ coverage should be used to minimize risks [24]. In a case report by Katz et al., fractional photothermolysis laser $1550 \mathrm{~nm}$ had been shown to be effective in a recalcitrant PIH with 3 sessions with 4-8 week interval [25]. Another case report from Turkey by Oram et al showed that fractional $\mathrm{CO}_{2}$ laser was beneficial for a recalcitrant PIH with two sessions [26].

\section{Conclusion}

The management of pigmentary disorders in darker skin is often challenging. Melasma and PIH are the most common problems in skin of colour. Firstly, one should identify and treat any underlying and/or contributing factors and have rational treatment goals. Sun protection is essential, and multi-therapy approach is needed in most cases. In most cases, especially superficial ones, first-line therapy is topicals with TC or newers. Second-line therapy is chemical peels with topicals. Lasers and light therapies should be used with special attention for the type of it, skin type and fluence. Low fluence q-switched Nd:YAG laser with $1064 \mathrm{~nm}$ has been reported with more benefits.

\section{References}

1. Sharma VK, Sahni K, Wadhwani AR (2013) Photodermatoses in pigmented skin. Photochem Photobiol Sci 12: 65-77.

2. Vashi NA, Kundu RV (2013) Facial hyperpigmentation: causes and treatment. Br J Dermatol 169: 41-56.

3. Cestari TF, Dantas LP, Boza JC (2014) Acquired hyperpigmentations. An Bras Dermatol 89: 11-25.

4. Desai SR, Alexis A (2014) Hyperpigmentation therapy: A review. J Clin Aesthet Dermatol 7: 13-17. 
5. Rivas S, Pandya AG (2013) Treatment of melasma with topical agents peels and lasers: an evidence-based review. Am J Clin Dermatol 14 359-376.

6. Draelos ZD (2007) Skin lightening preparations and the hydroquinone controversy. Dermatol Ther 20: 308-313.

7. Cestari T, Arellano I, Hexsel D, Ortonne JP (2009) Latin American Pigmentary Disorders Academy. Melasma in Latin America: options for therapy and treatment algorithm. J Eur Acad Dermatol Venereol 23: 760-772.

8. Davis EC, Callender VD (2010) Postinflammatory hyperpigmentation: a review of the epidemiology, clinical features, and treatment options in skin of color. J Clin Aesthet Dermatol 3: 20-31.

9. Chan R, Park KC, Lee MH, Lee ES, Chang SE, et al. (2008) A randomized controlled trial of the efficacy and safety of a fixed triple combination (fluocinolone acetonide $0.01 \%$, hydroquinone $4 \%$, tretinoin $0.05 \%$ ) compared with hydroquinone $4 \%$ cream in Asian patients with moderate to severe melasma. Br J Dermatol 159: 697-703.

10. Kandhari R, Khunger N (2013) Skin lightening agents - Use or abuse? - A retrospective analysis of the topical preparations used by melasma patients of darker skin types. Indian J Dermatol Venereol Leprol 79: 701-702.

11. Malek J, Chedraoui A, Nikolic D, Barouti N, Ghosn S, et al. (2013) Successful treatment of hydroquinone-resistant melasma using topical methimazole. Dermatol Ther 26: 69-72.

12. Kolbe L, Mann T, Gerwat W, Batzer J, Ahlheit S, et al. (2013) 4-nbutylresorcinol, a highly effective tyrosinase inhibitor for the topical treatment of hyperpigmentation. J Eur Acad Dermatol Venereol 27: 19-23.

13. Bhatia A, Hsu JTs, Hantash BM (2014) Combined topical delivery and dermalinfusion of decapeptide-12 accelerates resolution of postinflammatory hyperpigmentation in skin of color. J Drugs Dermatol 13: 84-85.

14. Salam A, Dadzie OE, Galadari H (2013) Chemical peeling in ethnic skin: an update. Br J Dermatol 169: 82-90
15. Grimes PE (1999) The safety and efficacy of salicylic acid chemical peels in darker racial-ethnic groups. Dermatol Surg 25: 18-22.

16. Grover C, Reddu BS (2003) The therapeutic value of glycolic acid peels in dermatology. Indian J Dermatol Venereol Leprol 69: 148-50.

17. Ilknur T, Biçak MU, Demirtaşoğlu M, Ozkan S (2010) Glycolic acid peels versus amino fruit acid peels in the treatment of melasma. Dermatol Surg 36: 490-495.

18. Moubasher AE, Youssef EM, Abou-Taleb DA (2014) Q-switched Nd: YAG laser versus trichloroacetic acid peeling in the treatment of melasma among Egyptian patients. Dermatol Surg 40: 874-872.

19. Konda S, Geria AN, Halder RM. New horizons in treating disorders of hyperpigmentation in skin of color. Semin Cutan Med Surg 31: 133-139.

20. Cho SB, Kim JS, Kim MJ (2009) Melasma treatment in Korean women using a 1064-nm Q-switched Nd:YAG laser with low pulse energy. Clin Exp Dermatol 34: 847-850.

21. Choi M, Choi JW, Lee SY, et al. (2010) Low-dose 1064-nm Q-switched $\mathrm{Nd}$ :YAG laser for the treatment of melasma. J Dermatolog Treat 21: 224-228.

22. Wattanakrai P, Mornchan R, Eimpunth S (2010) Low-fluence Qswitched neodymium-doped yttrium aluminum garnet $(1,064 \mathrm{~nm})$ laser for the treatment of facial melasma in Asians. Dermatol Surg 36: 76-87.

23. Chung JY, Choi M, Lee JH, Cho S, Lee JH (2014) Pulse in pulse intense pulsed light for melasma treatment: a pilot study. Dermatol Surg. 40: 162-168.

24. Wanitphakdeedecha R, Keoprasom N, Eimpunth S, Manuskiatti W (2014) The efficacy in melasma treatment using a $1410 \mathrm{~nm}$ fractional photothermolysis laser. J Eur Acad Dermatol Venereol 28: 293-297.

25. Katz TM, Goldberg LH, Firoz BF, Friedman PM (2009) Fractional photothermolysis for the treatment of postinflammatory hyperpigmentation. Dermatol Surg 35: 1844-1848.

26. Oram Y, Akkaya AD (2014) Refractory Postinflammatory Hyperpigmentation Treated Fractional CO2 Laser. J Clin Aesthet Dermatol 7: 42-44 